\title{
Performance and flow fields of a supersonic axial turbine at off-design conditions
}

\author{
Aki Grönman, Teemu Turunen-Saaresti, Pekka Röyttä, Ahti Jaatinen and Jari Backman \\ Institute of Energy, Lappeenranta University of Technology, P.O. Box 20, FI-53851, \\ Lappeenranta, Finland
}

\begin{abstract}
The increasing demand of energy efficiency and the utilization of small-scale energy sources require efficient, small, and versatile turbines. Supersonic turbines have a high power density and therefore small size and fewer stages than the subsonic ones. However, the performance of a supersonic turbine can decrease rapidly when operating at off-design conditions. This raises a need for the improvement of the turbine offdesign performance. In this paper, a supersonic axial flow turbine is studied numerically to find the causes of efficiency decrement. This paper presents the most throughout study so far about the reasons that lead to the decreased off-design performance with supersonic axial flow turbines and explains the loss sources individually for the stator and the rotor. Three operating conditions are studied, and it is suggested that at the lower than design pressure ratios, the shock losses of the stator decrease while simultaneously the stator secondary losses increase. The high positive incidence at the
\end{abstract}


lowest modelled pressure ratio, mass flow, and rotational speed caused a significant decrease in the rotor and stage performance. This highlights the importance of incidence even in shock driven supersonic turbine flows.

Keywords: axial turbine, supersonic flow, off-design

\section{INTRODUCTION}

Supersonic turbines are especially suitable for designs where the space is limited and high power is desired. Supersonic turbine stages are traditionally used in the turbo pumps of space rockets and in the Curtis stage of industrial steam turbines. Another application where a supersonic turbine is utilized is the Organic Rankine Cycle (ORC). ORC power plants are used when utilizing low temperature heat sources, such as geothermal heat or engine exhaust gases.

Supersonic turbines are usually impulse turbines, and they often operate at lower efficiencies than subsonic turbines with the same power. Efficiencies lower than $50 \%$ have been reported by Dorney et al. [1], [2]. One reason for the lower efficiencies is the occurrence of shock waves. Dorney et al. [1] compared two turbine geometries and concluded that one reason for the efficiency difference was the strength of the shock system in the stator and rotor. 
Yasa et al. [3] performed a study with a transonic axial turbine at several operating conditions. They found a high increase $\left(4^{\circ}\right.$ to $\left.19^{\circ}\right)$ in the positive rotor incidence when the rotational speed was decreased from the nominal speed to the lowest rotational speed. Their results also indicate that at the lowest rotational speed (with an approximately constant pressure ratio), the effect of the incidence becomes more important than the stator shocks. When the pressure ratio was altered and the rotational speed was kept constant, the increase in the pressure ratio led to more oblique stator trailing edge shock waves. The increasing pressure ratio turned the rotor incidence more positive. With the highest pressure ratio, the loss coefficients of Kacker and Okapuu [4] predicted high rotor trailing edge shock losses causing a drop in the predicted efficiency. Yasa et al. [3] also noted that this phenomenon was not detected in the efficiency measurements, probably because of the total pressure measurement uncertainty.

In a paper of Woinowsky-Krieger et al. [5], a transonic axial turbine was studied both experimentally and numerically. They found out that the turbine efficiency was only mildly affected by the pressure ratio. However, the efficiency had a relatively drastic drop at speeds below the design speed. They also found an 8 degree increase in the rotor blade incidence as the turbine speed changed from nominal 100 to 80 per cent. 
Snedden et al. [6] studied a single-stage turbine at off-design conditions. Even though the investigated turbine was a low speed machine, the results are relevant to the current study since the effect of the incidence seems to be generally similar with or without shock waves in the flow. They found that the relative rotor outlet flow angle was lower than the design value at the shroud and higher than the design value at the hub when the rotor incidence was $-5^{\circ}$. The importance of the incidence for the turbine performance seems to be high, and a high positive incidence can lead to increased total pressure losses as indicated in a paper of Jouini et al. [7]. They discussed that an incidence approaching $+10^{\circ}$ can lead to increased suction surface boundary layer loss production on the forward part of the blade, thus causing a small rise in the losses. A study of Benner et al. [8] also indicates that the losses that are caused by a positive incidence start increasing rapidly approximately at the incidence of $+10^{\circ}$.

In a paper of Munday et al. [9], supersonic nozzles were studied at design and offdesign Mach numbers. The shock waves were shown to be turned more towards the downstream direction when the exit Mach number was increased.

Despite these studies, there is still a clear lack of data that would cover also supersonic axial turbines that operate at off-design conditions and give detailed information about the flow fields and causes of efficiency decrement. In a previous study by the authors 
with a supersonic axial flow turbine [10], the effect of changing the axial gap between the stator and the rotor was examined. It was found that the efficiency of the turbine decreases rapidly when the turbine is operated below the design mass flow, pressure ratio, and rotational speed. The efficiency drop with the increasing axial gap was also found to be steeper at the off-design conditions. The main reason for the decreasing efficiency was concluded to be the increase of total pressure losses at the axial gap. It was also mentioned that the increased total pressure losses originate most likely from the increased mixing of shock waves, stator wakes, and the main flow.

The main objective of this study is to find the reasons that cause the degradation of the turbine efficiency at off-design conditions. The paper starts with an introduction where the objective of the study is derived. This is followed by the presentation of the used research methods in Chapter 2. After this, the studied geometries are presented in Chapter 3. The fourth chapter presents the results that can be divided into two topics. In the beginning, a transonic turbine cascade is modelled in order to demonstrate the reliability of the used code with shock waves. In the second part of Chapter 4 , the performance and flow fields of a supersonic turbine stage are studied at three different operating conditions. This is followed by conclusions and recommendations in Chapter 5. 


\section{NUMERICAL METHODS}

The Navier-Stokes solver Finflo is used in this study. Finflo is a multi-grid solver developed at the Aalto University School of Science and Technology. It employs the finite-volume method for spatial discretization and uses a constant specific heat capacity at constant pressure. The fluid is modelled as an ideal gas, but Finflo is capable of modelling real gases as well.

Finflo uses Roe's flux difference splitting method [11] for inviscid fluxes and the thinlayer approximation for viscous fluxes. For the primary flow variables and conservative turbulent variables, the MUSCL type approach is used, and the DDADI-factorization [12] is used to integrate the discretized equations in time.

In this study, Chien's $k-\varepsilon$ turbulence model [13] without wall functions has been used. More detailed information about Finflo and different numerical methods can be found e.g. in a paper of Siikonen [14].

The interface between the stator and rotor is modelled with the frozen rotor approach which causes error in the modelling of the stator-rotor interaction. This can be considered to be the biggest drawback of the chosen modelling approach, but the 
relative differences between different operating conditions can be expected to be comparable. This method has been successfully used and validated with Finflo in rotating machines previously in compressor studies by Jaatinen [15]. The code has also been successfully used in supersonic real gas flow modelling on an ORC-turbine nozzle e.g. by Harinck et al. [16], Turunen-Saaresti et al. [17], and Hoffren et al. [18].

Uniform momentum and total enthalpy distributions are defined as the inlet boundary conditions, and a constant static pressure distribution is used as the boundary condition at the outlet. These inlet and outlet boundary conditions are used both in the transonic cascade and supersonic turbine stage modelling. Where applicable, periodic boundaries are used in the transonic cascade and cyclic boundaries in the turbine stage modelling. The used boundary conditions in the modelling of the transonic cascade are presented in Fig. 1. Additionally, the hub and shroud walls are modelled as solid walls.

During the simulations, the convergence is monitored by following the mass flow difference between the inlet and outlet, and the mass flow is considered to be converged when the difference is stabilized. In addition, the L2-norms of density, momentum in all three directions, and energy residuals are important convergence parameters. 


\section{STUDIED GEOMETRIES}

\subsection{Transonic Turbine Cascade}

To demonstrate the reliability of the current study, a transonic turbine cascade is modelled with Finflo. This modelling gives information about the code performance with shock waves. The results are compared with the baseline geometry of a transonic turbine profile presented by Sonoda et al. [19].

The numerical model has two calculation blocks - one block covers one flow channel. The total number of cells is 3014656 and the non-dimensional wall distance is less than unity in the blade surfaces. The grid is structured with rectangular elements. In the rounded trailing edge, there is a total of 2048 cells.

Three measurement planes are defined for this study and are schematically shown in Fig. 1. More detailed information about the setup is available in Sonoda et al. [19]. Measurement planes SS-37 and SS-02 are perpendicular to the suction surface, starting from suction surface positions $x / c_{\mathrm{ax}}=0.759$ and $x / c_{\mathrm{ax}}=0.993$, respectively. Measurement plane 2 downstream the cascade is located at $x / c_{\mathrm{ax}}=1.325$. The static pressure along the blade surface and the total pressure variations at measurement planes SS-37 and SS-02 are taken from the midspan. Otherwise, mass flow averaged values are used. The blade 
inlet flow angle $\alpha_{1}$ is $65^{\circ}$ and the isentropic Mach number is 1.2 at measurement plane

2.

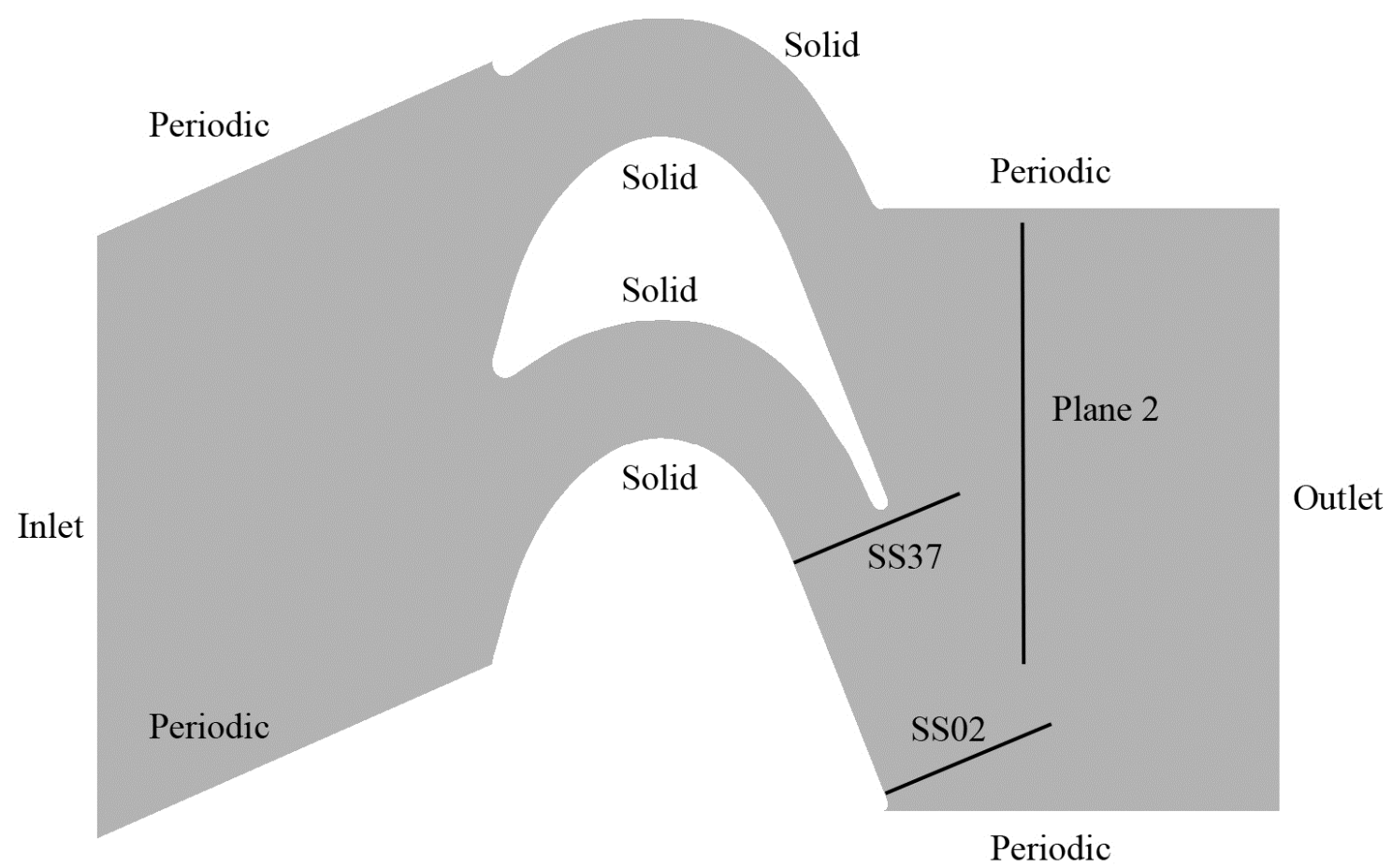

Fig. 1 The modelled geometry of transonic turbine cascade with boundary conditions and measurement planes from Sonoda et al. [19].

\subsection{Supersonic Turbine}

The turbine under investigation is a low reaction supersonic axial turbine without twist in the rotor blades. The turbine was designed for the turbocharger of a diesel engine. The main geometrical parameters of the turbine are presented in Table 1 . The stator is designed to have a supersonic absolute outlet velocity with a constant flow angle in the 
circumferential direction along the outlet. The flow inside the stator is turned at the converging section and only accelerated in the diverging section. The absolute flow angle at the rotor outlet is designed to be axial. The rotor blades have longer axial chord at the hub than at the shroud (see Fig. 2). It should also be noted that the relative velocity entering the rotor is subsonic and the rotor blade setting angle is constant with an incidence of $-3^{\circ}$.

Table 1 Supersonic turbine geometry.

\begin{tabular}{ll}
\hline Number of stator vanes & 20 \\
Number of rotor blades & 35 \\
Meanline degree of reaction & 0.15 \\
Stator design outlet flow angle from axial direction, $\alpha_{2}\left(^{\circ}\right)$ & 78 \\
Stator design outlet Mach number, $\mathrm{M}_{2}$ & 1.41 \\
Rotor design inlet flow angle from axial direction, $\beta_{2}\left(^{\circ}\right)$ & 56.6 \\
Rotor design outlet flow angle from axial direction, $\beta_{3}\left(^{\circ}\right)$ & 69.1 \\
\hline
\end{tabular}

The geometry of the turbine under investigation is shown in Fig. 2. The inlet boundary is located $270 \%$ of the stator axial chord upstream from the stator leading edge. Position 1 is located slightly downstream from the inlet boundary face. Positions 2 and 3 are located at the rotor leading and trailing edges, respectively. Position 4 at the diffuser outlet is situated slightly upstream from the outlet boundary. 


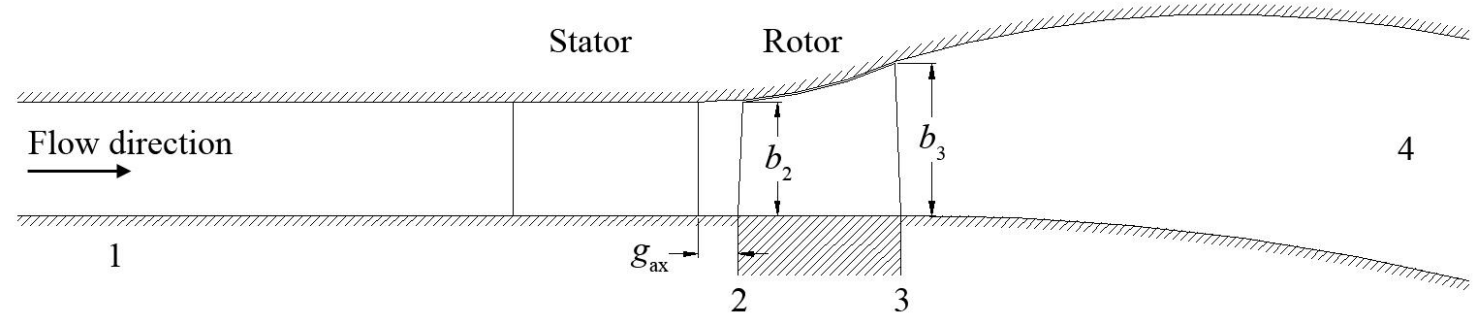

Fig. 2 Turbine geometry under investigation [10].

An example of the surface grid is shown in Fig. 3. Every second gridline is invisible for clarity. The calculation domain has 39 blocks, and there is one block for each stator channel and one for each rotor channel. Four stator channels and seven rotor channels are modelled, corresponding to a $1 / 5$ of the real turbine geometry. The tip clearance (1.9\% of $\left.b_{\text {rotor }}\right)$, the annular inlet part, and the annular diffuser are also modelled. For the tip clearance there is an individual calculation block for each blade that has $24 \times 8 \times 56$ nodes. The bottom of the calculation block is treated as a rotational solid (blade tip) and the casing as a solid wall. The non-dimensional wall distance for the design conditions is less than 3 at the rotor blade surface. The grid is structured with rectangular elements. 


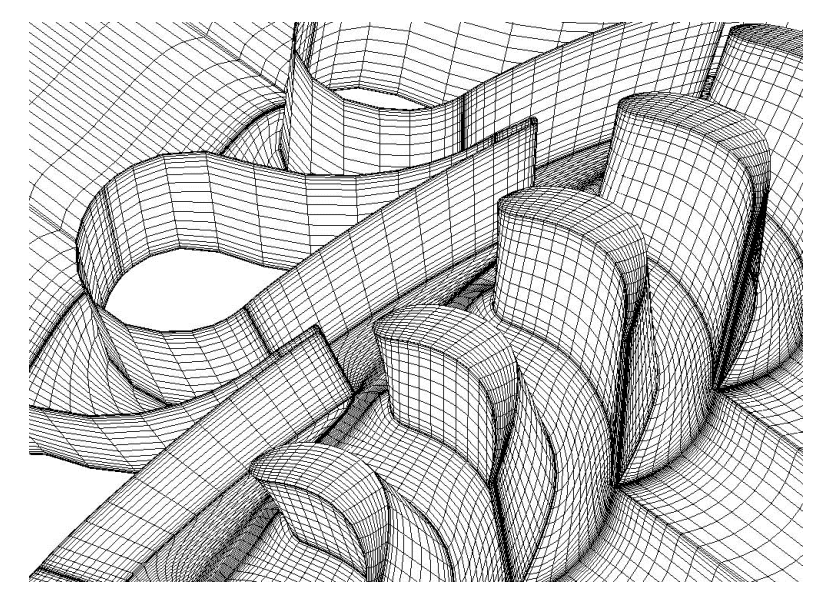

Fig. 3 Part of the surface grid, every second gridline is visible for clarity [10].

The modelled operating conditions and characteristics of the grids are presented in Table 2. The design and medium operating conditions are relatively close to each other, whereas the third operating condition has a clearly lower mass flow, pressure ratio, and rotational speed. The values for the design conditions are taken from process simulations, and for off-design conditions, measured values are used. These measurements were conducted with the turbine installed in a turbocharger and connected to a diesel engine. Since only limited pressure and temperature data was available with acceptable accuracy from the measurements, the transonic cascade measurements of Sonoda et al. [19] were chosen to be used to demonstrate the reliability of the used code with shock waves. The pressure ratio at medium conditions is slightly higher in the modelling than it was in the measurements (4.05), but it is still believed to give results that represent the real operating conditions. 
Table 2 Modelled turbine operating conditions and geometries.

\begin{tabular}{llllll}
\hline & $q_{\mathrm{m}}(\mathrm{kg} / \mathrm{s})$ & $\pi$ & $N(\mathrm{r} / \mathrm{min})$ & Blocks & Cells \\
\hline Design & $1.0 q_{\mathrm{m}, \mathrm{des}}$ & 5.6 & 31500 & 39 & 2601984 \\
Medium & $0.84 q_{\mathrm{m}, \mathrm{des}}$ & 4.25 & 28500 & 39 & 2601984 \\
Low & $0.49 q_{\mathrm{m}, \text { des }}$ & 2.55 & 23010 & 39 & 2601984 \\
& & & & & \\
\hline
\end{tabular}

A grid independency test is presented in Grönman and Turunen-Saaresti [10]. Although their study showed that full grid independency was not achieved, it is believed that the results are comparable since the grid used at different operating conditions is the same in every case.

\section{RESULTS}

\subsection{Cascade Modelling}

The calculated isentropic Mach number along the turbine profile is compared with the measurements of Sonoda et al. [19] in Fig. 4. At the pressure surface, there is in general a good accordance between the measurements and the numerical case. At the suction surface, CFD predicts slightly lower isentropic Mach numbers than the measurements from the leading edge, until $x / c_{\mathrm{ax}}=0.77$. Sonoda et al. [19] reported also nearly similar 
results since they found that the calculated Mach number was lower than the measured values at the front part of the blade surface.

Larger differences between the modelled case and measurements are noticeable close to the trailing edge. The numerical model seems to be unable to fully predict the reflected shocks and compression waves at the suction surface which makes the curve flat compared to the drop in the measured value at $x / c_{\mathrm{ax}}=0.93$. In general, Finflo is capable of modelling the blade surface pressure distribution with reasonably good agreement with the measurements.

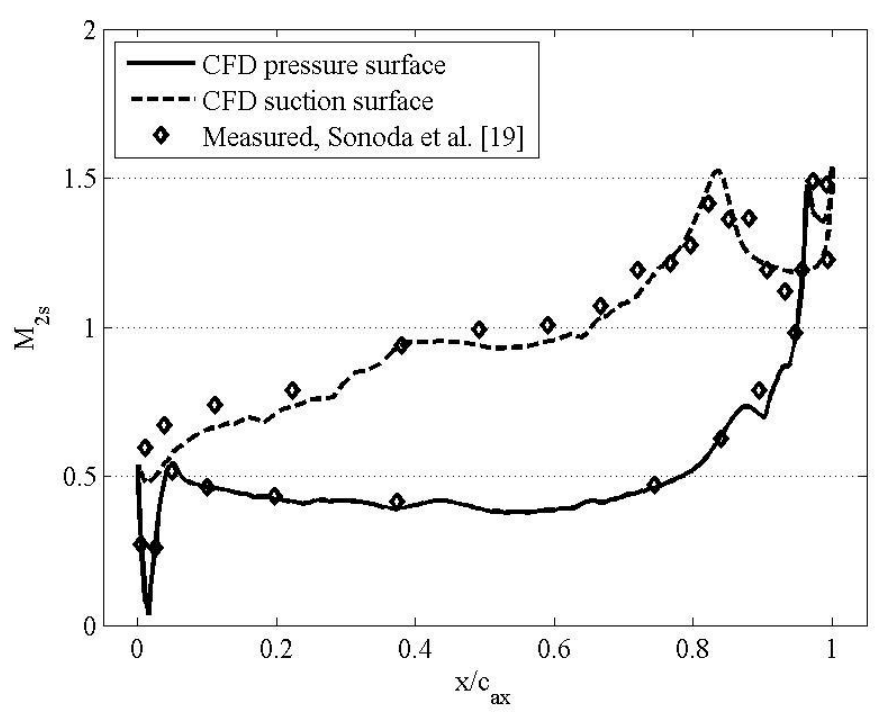

Fig. 4 Isentropic Mach number distribution along the turbine blade surface. 
To study how well Finflo predicts losses in transonic cascade, the losses in the total pressure are compared with the measurements. The total pressure loss $\omega$ is calculated using equation

$$
\omega=1-\frac{p_{\mathrm{t}}}{p_{\mathrm{t} 1}}
$$

The total pressure loss profile at plane SS-37 is plotted in Fig. 5 (a). Losses are well predicted between the suction surface and the wake, but the wake is wider than the measurements indicate. The loss peak from the wake is wider than the measured also at plane SS-02 in Fig. 5 (b). This indicates that the numerical model is not able to fully predict the wake flow area with the current grid density. Therefore, it is beneficial to develop a denser grid in that area in the future models. The losses between the wake and suction surface are partly underpredicted. This is caused by the weaker than measured shocks and reflections from the suction surface and their mixing with the main flow. The effect of the trailing edge shock wave in Fig. 5 is predicted by the CFD simulation as a high loss area starting from the suction surface. Although the losses are higher than in the measurements, the position of the trailing edge shock is reasonably well predicted. Overall, the agreement between the measurements and CFD is reasonably good. In general, it can be said that the numerical diffusion that is caused by the coarse grid and upwind method dampens the shock waves which is unphysical. However, the 
locations of the shock wave are predicted well and the relative differences can be considered to be comparable.

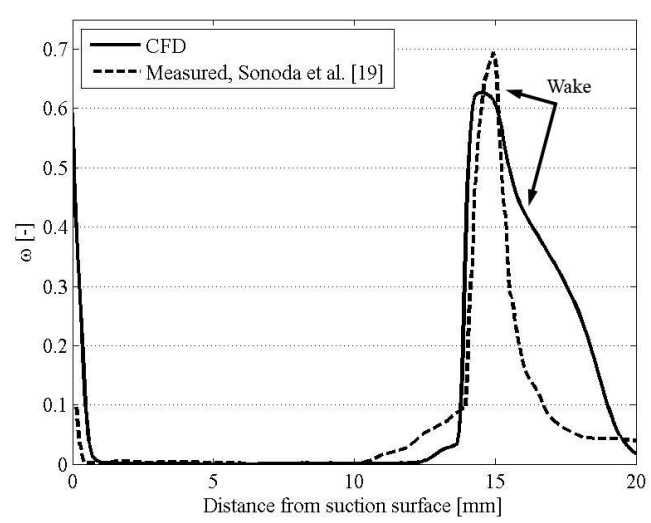

(a)

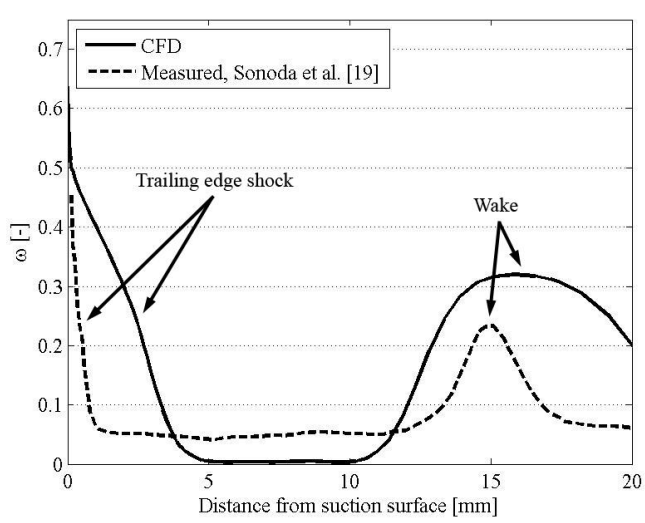

(b)

Fig. 5 Total pressure loss profile at planes SS-37 (a) and SS-02 (b).

\subsection{Turbine Stage Performance at different operating conditions}

The isentropic total-to-static efficiency is used to compare the performance of the turbine stage at different operating conditions and is defined as

$$
\eta_{\mathrm{s}, \mathrm{t}-\mathrm{s}}=\frac{T_{\mathrm{t} 1}-T_{\mathrm{t} 4}}{T_{\mathrm{t} 1}-T_{4 \mathrm{~s}}}
$$

The performance of the stator and rotor is evaluated by calculating the stator and rotor isentropic efficiencies by Equations (4.3) and (4.4), respectively.

$$
\eta_{\mathrm{s}, \mathrm{stator}}=\frac{T_{\mathrm{t} 1}-T_{2}}{T_{\mathrm{t} 1}-T_{2 \mathrm{~s}}}
$$




$$
\eta_{\mathrm{s}, \mathrm{rotor}}=\frac{T_{\mathrm{t} 2}-T_{\mathrm{t} 3}}{T_{\mathrm{t} 2}-T_{3 \mathrm{~s}}}
$$

All thermodynamic and flow properties are mass flow averaged values, except the static pressures that are used to calculate the isentropic Mach number distributions. The efficiencies for the stator, rotor, and full turbine stage are presented in Table 3 for all three modelled cases. The results show that the turbine performs with the highest efficiency at a slightly lower rotational speed $(28500 \mathrm{rpm})$ than it was designed for (31500 rpm). These two elevated efficiency values are still relatively close to each other when compared to the efficiency at the lowest rotational speed. When the causes for different stage performance are studied more in detail, it can be seen that the difference between the design and medium conditions comes from both stator and rotor performances, whereas the main reason for the poor performance under low conditions is the decreased rotor performance. It is also interesting to notice that the stator operates well even under the low operating conditions. 
Table 3 Efficiency of different components in the turbine stage.

\begin{tabular}{llll}
\hline & $\eta_{\mathrm{s}, \mathrm{stator}}$ & $\eta_{\mathrm{s}, \mathrm{rotor}}$ & $\eta_{\mathrm{s}, \mathrm{t}-\mathrm{s}}$ \\
\hline Design & 0.921 & 0.735 & 0.721 \\
Medium & 0.929 & 0.742 & 0.737 \\
Low & 0.919 & 0.693 & 0.671 \\
& & & \\
\hline
\end{tabular}

\subsection{Stator Flow Fields at Different Operating Conditions}

To be able to explain the reasons for the differences between the operating conditions from the previous chapter, it is necessary to look at the flow fields. The spanwise Mach number distribution at the stator outlet in Fig. 6 is almost similar between the two highest pressure ratios. As the pressure ratio decreases to the lowest value, the Mach number becomes relatively low. This is reasonably well in agreement with the changes in the isentropic Mach numbers that are calculated from total-to-static pressure ratios over the stator. Isentropic values for Mach numbers are 1.6 for design, 1.5 for medium, and 1.3 for low operating conditions. Higher Mach numbers lead to higher shock losses at the design and medium conditions, when compared to low operating conditions. The amount of losses that originate from the trailing edge shocks is a function of outlet Mach number [4]. The average stator outlet Mach number for design and medium operating conditions is 1.5 . 


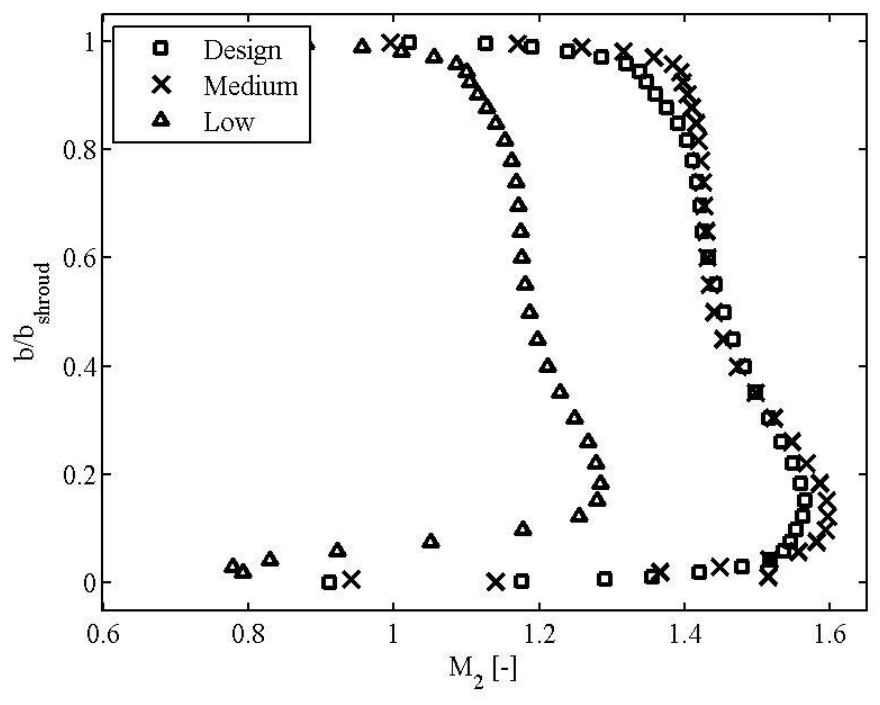

Fig. 6 Spanwise stator outlet Mach number distribution at different operating conditions.

In Fig. 7 , the contours of the total pressure loss at 2.7 per cent of stator axial chord downstream from the stator trailing edge are presented for the design and low operating conditions. Large areas of increased secondary losses are noticeable especially at the hub side at low operating conditions downstream of the stator trailing edge. The explanation for these losses can be found by looking at the isentropic Mach number distributions at the stator surface in Fig. 8. 


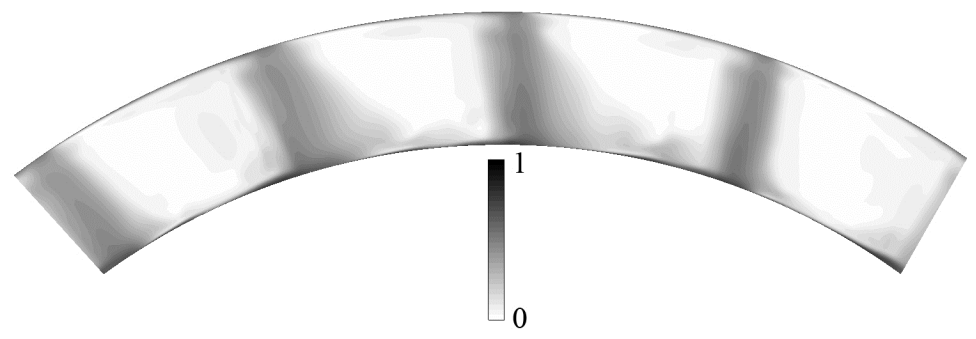

(a)

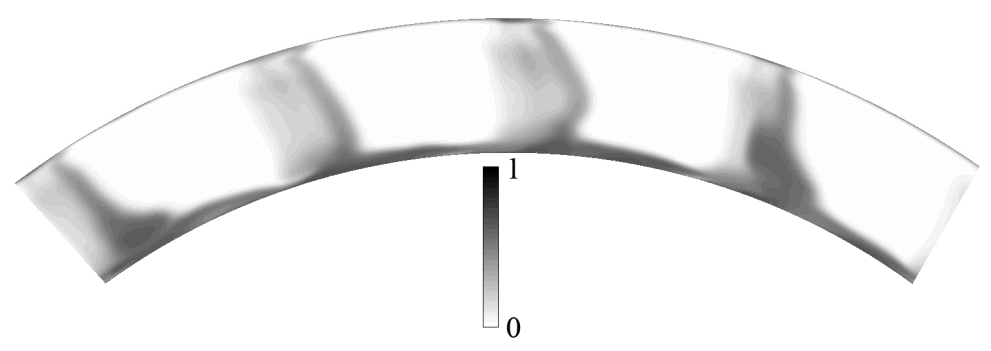

(b)

Fig. 7 Contours of total pressure loss 2.7 per cent of stator axial chord dowstream from the stator trailing edge, (a) design and (b) low operating conditions.

In Fig. 8, the isentropic Mach number distribution at the stator midspan is plotted over the stator axial length. The shape of the distribution is similar also at the hub and shroud, and therefore only the midspan is presented here. In general, the isentropic Mach number is similar between different operating conditions for the majority of the stator surface, and the differences are located in the supersonic section. The change in the position of the trailing edge shock is noticeable when the peak in the isentropic Mach number moves in the upstream direction. The position of the shock peak is at 
$x / c_{\mathrm{ax}}=0.87$ for the design and $x / c_{\mathrm{ax}}=0.78$ for the low flow conditions. Similar behaviour was also found in papers of Jouini et al. [7], Munday et al. [9], and Yasa et al. [3]. At the low flow conditions, the loading of the stator is greatly affected by the trailing edge shock, and the isentropic Mach number at the suction surface stays almost constant downstream from $x / c_{\mathrm{ax}}=0.85$. These results indicate that a more perpendicular shock wave leads to lower stator loading close to the trailing edge which causes the increase in the secondary losses shown in Fig. 7.

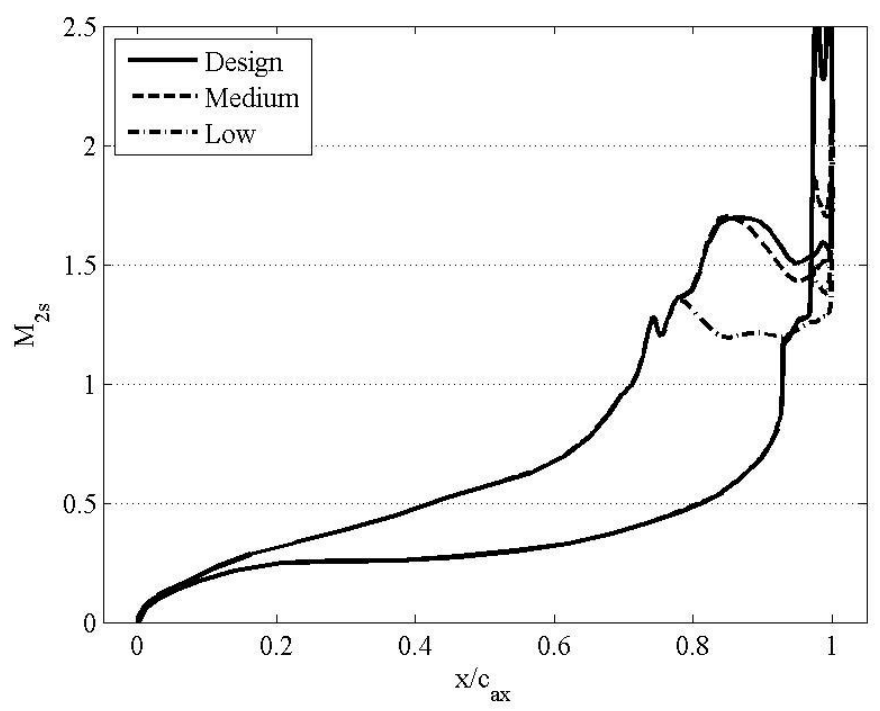

Fig. 8 Isentropic Mach number distribution at the stator midspan with different operating conditions.

The efficiency of the stator is almost similar at design and low conditions, but the secondary losses are more evident at low conditions. This indicates that the decreased 
shock losses due to lower pressure ratio are replaced by the increased secondary losses. These losses are caused by the decreased loading at the stator suction surface due to more perpendicular trailing edge shock waves. At the design conditions the behaviour is opposite with higher shock losses and lower secondary losses. The importance of the shock wave related losses was also mentioned by Dorney et al. [1].

Rough estimations of the boundary layer loss sources are given in Tables 4 and 5 for the stator and rotor, respectively. The share of losses is calculated based on the assumption that blade row losses are proportional to $\int U^{3} d A$ as presented by Harrison [20]. Freestream velocities are derived from the inlet stagnation pressure and local static pressure following Harrison [20]. This causes error in the evaluation of the free-stream velocity due to relatively high Mach numbers, but the relative values are expected to be comparable. Table 4 indicates that the boundary layer losses are divided similarly between the design and medium conditions, but at the low operating conditions, the percentage of losses at the suction surface decreases and losses at the pressure surface increase. This is caused by the decreased loading close to the trailing edge due to more perpendicular trailing edge shock waves. In general, most of the losses are generated at the suction surface. At the rotor, the differences between the different operating conditions are negligible as shown in Table 5. Most of the losses originate from the 
suction surface, but the share of pressure surface and shroud endwall losses is larger than in the stator.

Table 4 Percentage of boundary layer losses at the stator surfaces (total losses 100\%).

\begin{tabular}{lcccc}
\hline & Suction & Pressure & Hub & Shroud \\
& surface & surface & wall & wall \\
& & & & \\
\hline Design & 61.0 & 11.9 & 13.2 & 13.8 \\
Medium & 60.8 & 11.8 & 13.5 & 14.0 \\
Low & 58.4 & 13.4 & 13.8 & 14.3 \\
& & & & \\
\hline
\end{tabular}

Table 5 Percentage of boundary layer losses at the rotor surfaces (total losses 100\%).

\begin{tabular}{lllll}
\hline & Suction & Pressure & Hub & Shroud \\
& surface & surface & wall & wall \\
\hline Design & 40.1 & 26.4 & 13.3 & 20.2 \\
Medium & 39.8 & 26.5 & 13.5 & 20.2 \\
Low & 40.0 & 26.6 & 13.5 & 19.9 \\
& & & & \\
\hline
\end{tabular}




\subsection{Rotor Flow Fields at Different Operating Conditions}

In Figs. 9 (a) and (b), the contours of the relative Mach number are plotted at the rotor outlet for the design and medium conditions. The areas of high Mach number at the rotor outlet at the design conditions are larger than they are at the medium conditions. At the low operating conditions in Fig. 9 (c), close unity Mach number areas are missing because of the lower pressure ratio, but there are low Mach number areas quite similar to the medium conditions. The areas of low Mach number are predicted at the suction surface shroud, and they are increasing at the off-design conditions. These areas are caused by the tip-clearance and secondary flows. The areas of low Mach number are also noticeable at the suction and pressure surfaces from hub towards the midspan at the low operating conditions. 


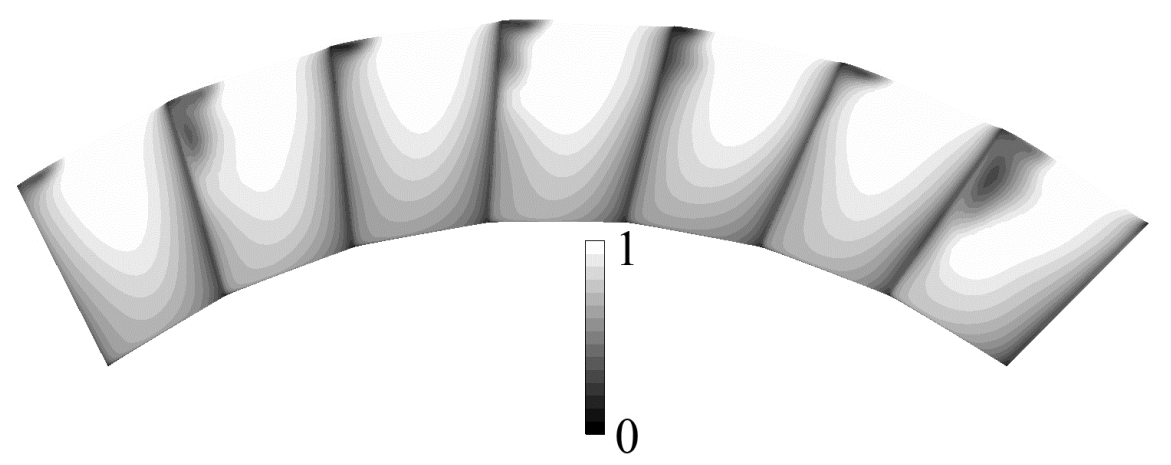

(a)

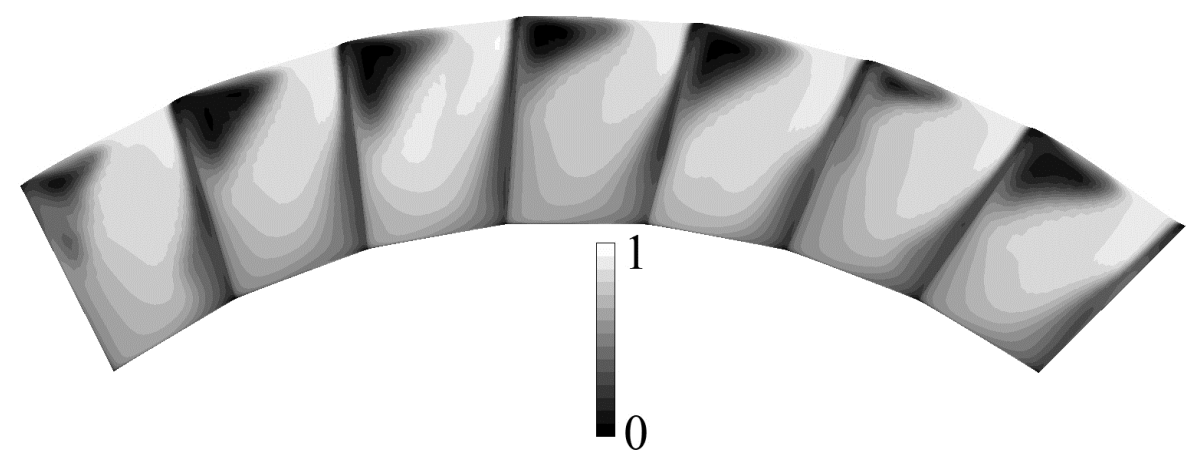

(b)

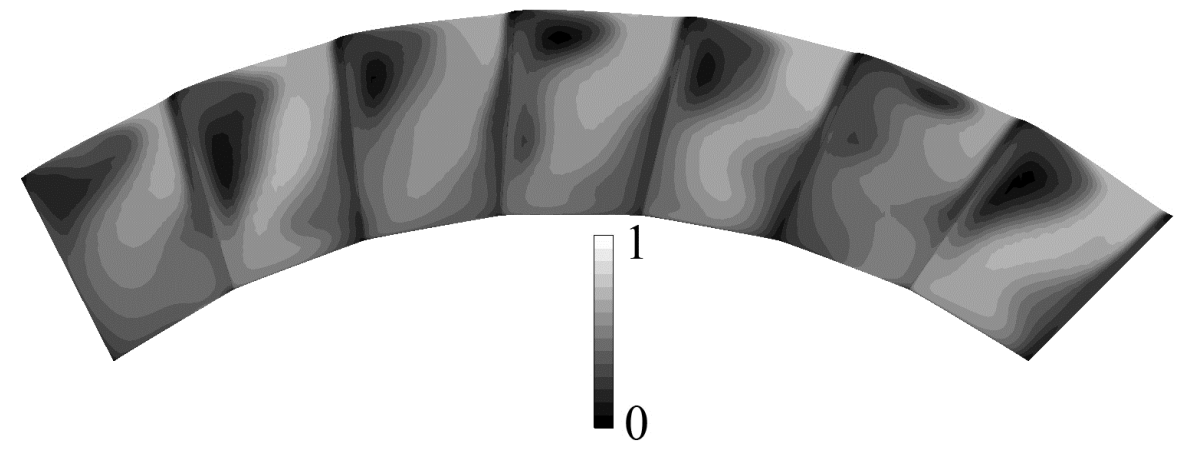

(c)

Fig. 9 Relative Mach number at the rotor outlet at (a) design, (b) medium, and (c) low operating conditions. 
Rotor incidence in Fig. 10 (a) is positive at the hub and negative closer to the tip. In a paper of He [21], it was also mentioned that the non-twist rotor blades lead to a negative incidence near the tip and a positive incidence near the hub. Woinowsky-Krieger et al. [5] reported that a transonic turbine had an 8 per cent increase in the blade incidence as the turbine rotational speed changed from 100 to 80 per cent. This is considered to be qualitatively in accordance with the results presented in Fig. 10 (a). The incidence is more uniform at the medium conditions than it is at the design, which gives an explanation for the improved rotor performance. The rotor trailing edge shocks might, however, cause slightly higher additional losses at the design conditions. The lower mass flow and rotational speed lead to a more positive incidence, and at low operating conditions, the incidence stays positive for most of the span. High positive incidence can lead to increased total pressure losses as indicated in a paper of Jouini et al. [7].

The relative flow angle at the rotor outlet is shown in Fig. 10 (b) along with the blade setting angle. When comparing the differences between the medium and low conditions, the largest difference is the relatively large overturning area at low conditions. This was also noticeable in Fig. 9 (c) when the low Mach number areas from hub towards the midspan increased. The reason for large overturning is the high positive incidence at the rotor leading edge. Positive effects of the suppression of overturning at the hub area were mentioned by Snedden et al. [6]. This explains why the performance of the rotor 
decreases at low operating conditions. Yasa et al. [3] found that with a low rotational speed, the importance of the rotor incidence is higher than the stator exit losses.

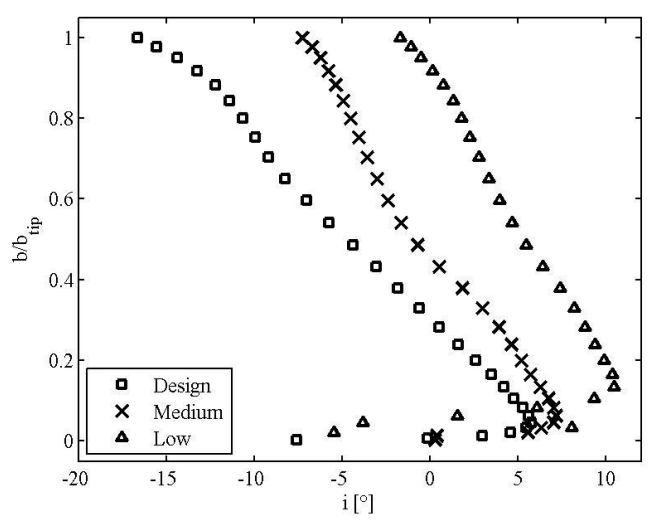

(a)

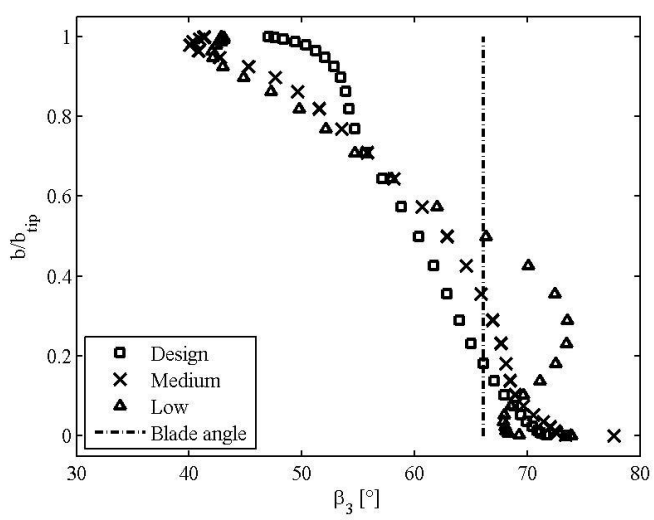

(b)

Fig. 10 Incidence at the rotor inlet (a) and relative flow angle at the rotor outlet (b).

\section{CONCLUSIONS}

This paper presents a throughout study about the reasons that lead to the decreased offdesign performance of a supersonic axial flow turbine. The unique feature of this study is the explanation of the loss sources individually for the stator and the rotor. The two most important loss sources in supersonic axial turbine flows were found to be the stator trailing edge shock waves and the positive rotor incidence.

In the beginning of the study, a transonic cascade was modelled in order to demonstrate the reliability of the modelling with shock waves. This study showed that a reasonably 
good accordance was achieved with the measurements. Especially the isentropic Mach number distribution along the blade surface was well predicted. Also the trends of total pressure losses were reasonably well predicted together with the position of the trailing edge shocks. Although, quantitatively, the losses differed from the measurements, it is considered to be acceptable since this study concentrates on trends, not on the exact values.

In the second part of the study, a supersonic low reaction axial turbine was modelled under the design and two off-design conditions. The performance of the turbine differed from the design state especially at the low pressure ratio and low rotational speed conditions. The study showed similar trends in the flow behaviour and loss sources with the open literature giving verification for the results. Two loss mechanisms were found to be dominant in the off-design performance of the stator and rotor.

At the stator the decrease in the pressure ratio from the design value decreases shock wave losses. However, simultaneously the stator secondary losses increase and lead to a need for the designer to optimise these beneficial and detrimental effects. The reason for the increased secondary losses is the decreased loading at the suction surface that is caused by the more perpendicular shock waves from the trailing edge. A rough estimation of the boundary layer loss sources also indicated that the percentage of losses 
decreased at the suction surface and increased at the pressure surface due to the lower loading.

The performance of the rotor was found to be strongly affected by the incidence. In the case of the lowest rotor efficiency, the high positive incidence led to a relatively large area of overturned flow at the rotor outlet. This explains why the performance of the rotor and the whole stage was lower than it was at the other operating conditions. It also highlights the importance of avoiding high positive incidences.

These loss sources can be used to explain the slightly better turbine performance at the medium off-design operating conditions which was attributed to the performance improvements in stator and rotor equally. The reason for the improved stator performance was that the decrease in shock losses due to the decreased pressure ratio overcame a simultaneous increase in secondary losses. With respect to the rotor, the performance was mainly improved because of the more uniform incidence.

It could be beneficial in the future to study experimentally the performance of a supersonic turbine at the off-design conditions and also to conduct more numerical modelling in order to verify the presented observations. In general, higher stage efficiencies can be achieved at design conditions by redesigning the turbine rotor with 
twist. One possible area for future research could be the use of variable stator geometry in supersonic axial flow turbines that could solve the presented stator trailing edge shock wave and rotor incidence problems. As a general recommendation for a designer, special attention should be paid to the position of the stator trailing edge shock waves and, if possible, a high positive rotor incidence should be avoided.

\section{ACKNOWLEDGEMENTS}

Authors would like to thank the Academy of Finland, the Finnish Graduate School in Computational Fluid Dynamics, and the Finnish Cultural Foundation, South Karelia Regional Fund.

\section{REFERENCES}

[1] Dorney, D. J., Griffin, L. W., and Huber, F. W. A Study of the Effects of Tip Clearance in a Supersonic Turbine. Journal of Turbomachinery, 2000, 122, 674683.

[2] Dorney, D. J., Griffin, L. W., Huber, F., and Sondak, D. L. Unsteady Flow in a Supersonic Turbine with Variable Specific Heats. Journal of Propulsion and Power, 2002, 18, 493-496. 
[3] Yasa, T., Paniagua, G. and Bussolin, A. Performance Analysis of a Transonic High-Pressure Turbine. Proc. IMechE, Part A: J. Power and Energy, 2007, 221, 769-778.

[4] Kacker, S. C. and Okapuu, U. A Mean Line Prediction Method for Axial Flow Turbine Efficiency. Journal of Turbomachinery, 1982, 104, 111-119.

[5] Woinowsky-Krieger, M., Lavoie, J.-P., Vlasic, E. P., and Moustapha, S. H. OffDesign Performance of a Single-Stage Transonic Turbine. Journal of Turbomachinery, 1999, 121, 177-183.

[6] Snedden, G., Dunn, D., Ingram, G., and Gregory-Smith, D. The Performance of a Generic Non-axisymmetric End Wall in a Single Stage Rotating Turbine at On and Off-Design Conditions. In: Proceedings of ASME Turbo Expo, Glasgow, UK, 2010, paper no. GT2010-22006.

[7] Jouini, D. B. M, Sjolander, S. A. and Moustapha, S. H. Aerodynamic Performance of a Transonic Turbine Cascade at Off-Design Conditions. Journal of Turbomachinery, 2001, 123, 510-518.

[8] Benner, M. W., Sjolander, S. A. and Moustapha, S. H. An Empirical Prediction Method for Secondary Losses in Turbines - Part I: A New Loss Breakdown Scheme and Penetration Depth Correlation. Journal of Turbomachinery, 2006, 128, 273-280. 
[9] Munday, D., Heeb, N., Gutmark, E., Liu, J., and Kailasanath, K. Supersonic Jet Noice Reduction Technologies for Gas Turbine Engines. Journal of Engineering for Gas Turbines and Power, 2011, 133, 101201.

[10] Grönman, A. and Turunen-Saaresti, T. Design and Off-Design Performance of a Supersonic Axial Flow Turbine with Different Stator-Rotor Axial Gaps. Proc. IMechE, Part A: J. Power and Energy, 2011, 225, 497-503.

[11]Roe, P. L. Approximate Riemann Solvers, Parameter Vectors and Difference Schemes. Journal of Computational Physics, 1981, 43, 357-372.

[12]Lombard, C. K., Bardina, J., Venkatapathy, E. and Oliger, J. MultiDimensional Formulation of CSCM - An Upwind Flux Difference Eigenvector Split Method for Compressible Navier-Stokes Equations. In: 6th AIAA Computational Fluid Dynamics Conference, Danvers, Massachusetts, 13-15 July 1983, AIAA paper no. 83-1895-CP, pp. 649-664.

[13] Chien, K. Y. Predictions of Channel and Boundary-Layer Flows with a LowReynolds-Number Turbulence Model. AIAA Journal, 1982, 20, 33-38.

[14] Siikonen, T. An Application of Roe's Flux-Difference Splitting for the $k-\varepsilon$ Turbulence Model. International Journal for Numerical Methods in Fluids, 1995, 21, 1017-1039. 
[15] Jaatinen, A. Performance Improvement of Centrifugal Compressor Stage with Pinched Geometry or Vaned Diffuser. Dissertation, Lappeenranta University of Technology, Finland, 2009.

[16] Harinck, J., Turunen-Saaresti, T., Colonna, P., Rebay, S. and van Buijtenen, J. Computational Study of a High-Expansion Ratio Radial Organic Rankine Cycle Turbine Stator. Journal of Engineering for Gas Turbines and Power, 2010, 132, 054501.

[17] Turunen-Saaresti, T., Tang, J., van Buijtenen, J. and Larjola, J. Experimental and Numerical Study of Real-Gas Flow in a Supersonic ORC Turbine Nozzle. In: Proceedings of ASME Turbo Expo, Barcelona, Spain, 2006, paper no. GT200691118

[18]Hoffren, J., Talonpoika, T., Larjola, J. and Siikonen, T. Numerical Simulation of Real-Gas Flow in a Supersonic Turbine Nozzle Ring. Journal of Engineering for Gas Turbines and Power, 2002, 124, 395-403.

[19] Sonoda, T., Arima, T., Olhofer, M., Sendhoff, B., Kost, F., and Giess, P.-A. A Study of Advanced High-Loaded Transonic Turbine Airfoils. Journal of Turbomachinery, 2006, 128, 650-657.

[20] Harrison, S. The Influence of Blade Lean on Turbine Losses. Journal of Turbomachinery, 1992, 114, 184-190. 
[21] He, L. Three-Dimensional Unsteady Navier-Stokes Analysis of Stator-Rotor Interaction in Axial-Flow Turbines. Proc. IMechE, Part A: J. Power and Energy, 2000, 219, 13-22.

\section{APPENDIX 1}

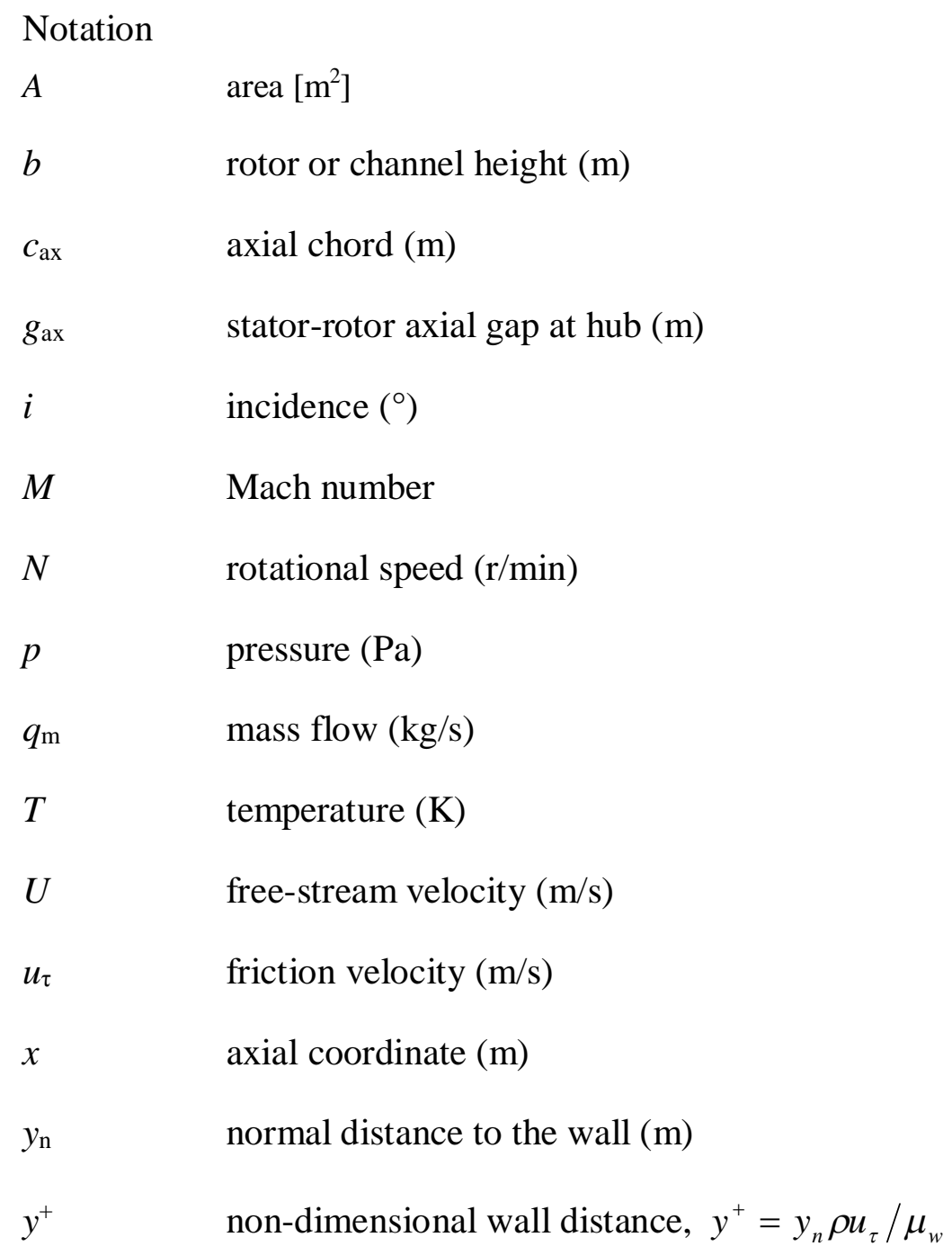




$\begin{array}{ll}\alpha & \text { absolute flow angle from the axial direction }\left(^{\circ}\right) \\ \beta & \text { relative flow angle from the axial direction }\left(^{\circ}\right) \\ \eta & \text { efficiency } \\ \mu_{\mathrm{w}} & \text { molecular viscosity on the wall }(\mathrm{kg} / \mathrm{m} / \mathrm{s}) \\ \pi & \text { total-to-static pressure ratio } \\ \rho & \text { density }\left(\mathrm{kg} / \mathrm{m}^{3}\right) \\ \omega & \text { total pressure loss coefficient }\end{array}$

Subscripts

des design

S isentropic

$\mathrm{t} \quad$ total

1 turbine inlet

2 stator outlet/rotor inlet

3 rotor outlet

4 diffuser outlet

Abbreviations
DDADI Diagonally Dominant Alternating Direction Implicit
MUSCL Monotonic Upwind Schemes for Conservation Laws 